\title{
The Correlation of Atherogenic Index of Plasma and Small Dense Low-Density Lipoprotein with the Degree of Coronary Artery Stenosis in Acute Coronary Syndrome
}

\author{
Yaswir Rismawati ${ }^{1}$, Efrida $^{2}$, Fadil Muhammad $^{3}$ \\ \{rismawatiyaswir@yahoo.com ${ }^{1}$,efridasppk@yahoo.com², mfadil98@yahoo.com ${ }^{3}$ \} \\ Department of Clinical Pathology, Faculty of Medicine, Andalas University/Dr. M. Djamil Hospital, \\ Padang, Indonesia ${ }^{1,2}$ \\ Department of Cardiology and Vascular Medicine, Faculty of Medicine, Andalas University/Dr. M. \\ Djamil Hospital, Padang, Indonesia ${ }^{3}$
}

\begin{abstract}
Atherogenic dyslipidemia triggers the formation of atherosclerotic plaque resulting in coronary artery stenosis. Atherogenic Index of Plasma (AIP) is a reflection of the degree of plasma atherogenicity and an indicator of the small dense LDL (sdLDL). Small dense LDL is a predictor of cardiovascular disease. This study aimed to determine the correlation between AIP and sdLDL with the degree of coronary artery stenosis in ACS.A cross-sectional designed analytic study was carried out on 70 ACS patients at Central Laboratory Installation of Dr. M. Djamil Hospital in Padang from April 2017 to June 2017. Examination of lipid profile was performed by using the colorimetric enzymatic method; examination of sdLDL was performed by using the ELISA method; while the degree of stenosis was determined by using coronary angiography examination. The mean levels of total cholesterol, LDL cholesterol, HDL cholesterol and triglycerides in ACS respectively were 178.7 (46.8) mg/dL, 108.9 (38.1) mg/dL, 35.7 (10.9) mg/dL and 151.2 (64.1) $\mathrm{mg} / \mathrm{dL}$. The mean value of AIP and sdLDL in ACS were $0.26(0.23)$ and 84.32 (18.32) $\mathrm{nmol} / \mathrm{mL}$. The median degree of coronary artery stenosis in ACS was $80 \%$ with a range of 50\%-99\%. Pearson correlation test showed that sdLDL had a significant and weak positive correlation with the degree of coronary artery stenosis in ACS $(r=0.446$; $\mathrm{p}<0.05$ ). The conclusion of this studySmall dense LDL is related to the degree of coronary artery stenosis in ACS.
\end{abstract}

Keywords: Atherogenic Index Plasma, Sdldl, The Degree of Stenosis, Acute Coronary Syndrome.

\section{Introduction}

Acute coronary syndrome (ACS) is a cardiac emergency caused by rupture or erosion of atherosclerotic plaques. The acute coronary syndrome can be manifested as unstable angina pectoris/UAP, acute myocardial infarction (AMI) either with ST-segment elevation (STsegment elevation myocardial infarction/STEMI) or without ST-segment elevation (non STsegment elevation myocardial infarction/NSTEMI).[1],[2] 
Coronary heart disease is the main and the first leading cause of all deaths in Indonesia. The results of Indonesia Basic Health Research (RISKESDAS) in 2013 showed the CHD prevalence of 0.55 in all patients with non-communicable diseases.[3]

The risk factors that is associated with the development of atherosclerosis and the occurrence of ACS are divided into modifiable risk factors, such as hyperlipidemia, hypertension, smoking, diabetes, and metabolic syndrome, and non-modifiable risk factors, such as age, sex, and history. Dyslipidemia is an increase in total cholesterol, a decrease in highdensity lipoprotein (HDL) cholesterol, an increase in low-density lipoprotein (LDL) cholesterol, and an increase in triglyceride (TG) levels. Increased LDL cholesterol level $>100 \mathrm{mg} / \mathrm{dL}$, decreased HDL cholesterol level $<40 \mathrm{mg} / \mathrm{dL}$ and increased triglycerides level $>150 \mathrm{mg} / \mathrm{dL}$ are the main risk factors for ACS associated with atherogenicity.[4],[5],[6]

Atherosclerosis is a major cause of CHD with multifactorial processes and interrelated mechanisms.[7],[8],[9] The formation of atherosclerotic plaques may cause narrowing of the arterial lumen, resulting in reduced vascular blood flow. The thrombosis usually occurs after the rupture of atherosclerotic plaques that will activate the platelets and the coagulation pathway. As the atherosclerotic plaques rupture, tear, and the subendothelial bleeding occurs, then the thrombogenic process will begin, blocking the coronary artery partially or completely. After the blockage occurs, various clinical presentations will appear, such as angina or myocardial infarction. This atherosclerosis process can be stable, but it can also be unstable or progressive. The consequence that can cause mortality is the unstable/progressive atherosclerosis process, also known as ACS.[10],[11]

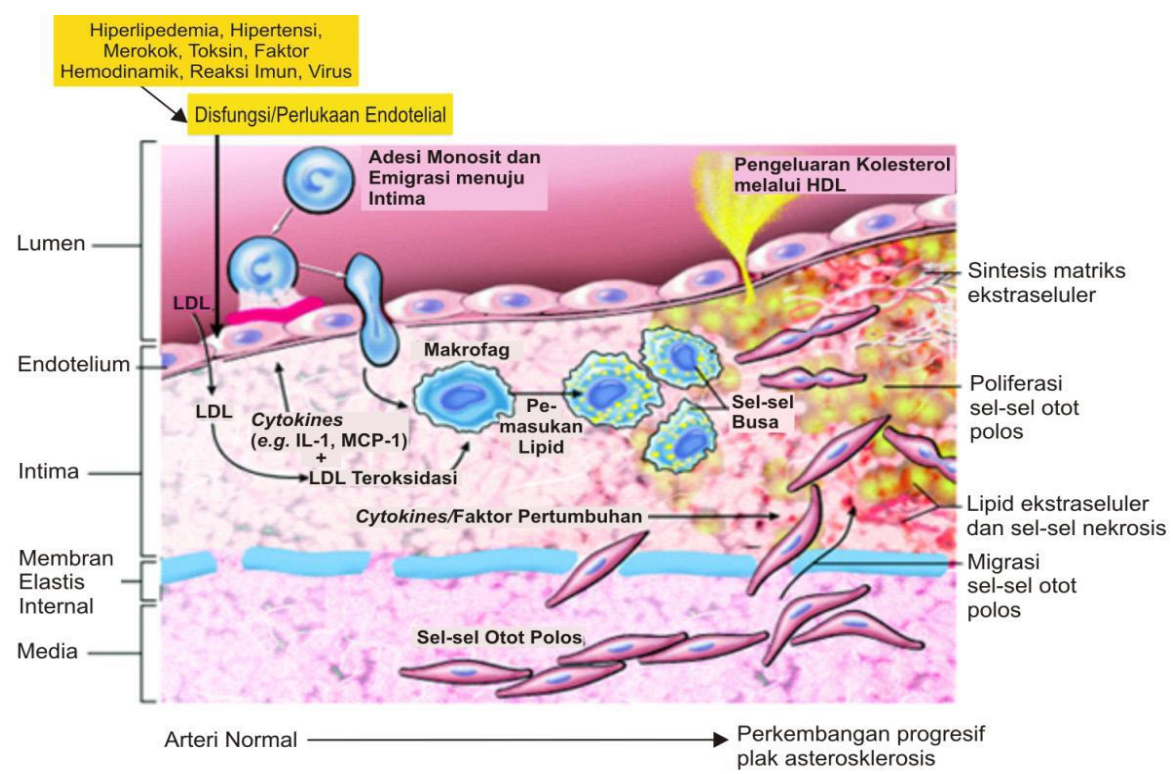

Fig. 1. The Pathogenesis of Atherosclerosis.[11]

The condition of the coronary artery in ACS can be examined by using an invasive examination method, namely coronary angiography (discovered in 1959). Coronary angiography is an invasive method of examination that was first performed by Sones, by inserting a catheter, injecting a contrast agent into the coronary artery, and capturing its radiographic images. Coronary angiography is very helpful in determining the diagnosis, prognosis, and subsequent 
management of cardiovascular treatment. Currently, coronary angiography has been one of the most commonly performed invasive procedures worldwide in the management of cardiovascular therapy.[1][2]

Increased LDL cholesterol level is the major risk factor for CHD. LDL particles are very heterogeneous, that varies in density, size and chemical composition. The biochemical structure of these particles determines the atherogenicity of LDL particles. Small dense LDL (sdLDL) is a small and dense LDL particle, with a pro-atherogenic property which means that it has the greater atherogenic ability because it can decrease the LDL receptor-mediated clearance, increase the resistance of arterial vascular walls, and increase the possibility of oxidation. The sdLDL-rich lipoprotein profiles are associated with a 3-fold increased risk of myocardial infarction compared with the large buoyant LDL. National Cholesterol Education Adult Treatment Panel III (NCEP-ATP III) has identified sdLDL as a risk factor for CHD.[6],[13]

Atherogenic Index of Plasma (AIP) is a description of plasma atherogenicity degree. Atherogenic index of plasma is defined as $\log$ (TG/HDL-C) in the molar. Atherogenic index of plasma is proposed as a marker of plasma atherogenicity because its value increases in individuals with a high risk of CHD. Atherogenic index of plasma correlates well with the size of LDL particles and can be used as the indicator of atherogenic lipoprotein phenotype. Atherogenic index of plasma is an sdLDL indicator. The atherogenic index of plasma can be used as a marker for the presence of sdLDL because the sdLDL examination is still limited, difficult, and expensive; while examination of triglycerides and HDL cholesterol is more available and affordable[14]. A study by Khazaal in 2013 reported that AIP was the index with the highest sensitivity to predict the incidence of ACS that was widely available and could be assessed easily so it became a better screening tool to evaluate the risk of ACS.[15]

It is important for the clinicians to know the markers that affect the coronary artery stenosis caused by atherosclerosis in ACS patients so that they can evaluate coronary artery stenosis in ACS patients earlier. Some parameters have been introduced to determine the presence of atherosclerosis but the best parameter in clinical applications is still debatable. Based on the background above, we were interested in determining the correlation between AIP and sdLDL with the degree of coronary artery stenosis in ACS in the cardiovascular care unit (CVCU) of Dr. M. Djamil Hospital, Padang.

\section{Method}

A cross-sectional analytic study was conducted in the Central Laboratory Installation of Dr. M. Djamil Hospital Padang from April 2017 to June 2017 totaling 70 samples.

Inclusion criteria are those who are willing to take the informed consent. Exclusion criteria are patients who do not fast more than 9 hours. Examination of total cholesterol, LDL cholesterol, triglycerides, and HDL cholesterol were performed by using the enzymatic colorimetric method; sdLDL examination was performed by using the ELISA method; while the degree of stenosis was determined by using coronary angiography examination. Pearson correlation test was used to analyze the correlation of lipid profile, AIP and sdLDL with the degree of coronary artery stenosis, significant if the p-value $<0.05$. 


\section{Results}

A cross-sectional designed analytic study was carried out on 70 patients with ACS who met the inclusion and exclusion criteria. The blood examination of the subjects was conducted in the Central Laboratory Installation of Dr. M. Djamil Hospital, Padang. The characteristics of the study subjects are listed in Table 1.

Table 1. The Characteristics of Study Subjects

\begin{tabular}{lll}
\hline Variables & $\mathrm{f}(\%)$ & Mean (SD) \\
\hline Gender & & \\
Male & $48(68,6)$ & \\
Female & $22(31,4)$ & $60,1(8,9)$ \\
Age (years) & & 6 \\
\hline
\end{tabular}

Table 1 shows that $68,6 \%$ of the study subjects were male. The results of lipid profile examination can be seen in Table 2 .

Table 2. Lipid Profile

\begin{tabular}{lllll}
\hline \multirow{2}{*}{ Parameters } & \multirow{2}{*}{ Mean (SD) } & & Range & \\
\cline { 4 - 5 } & & & Minimum & Maximum \\
\hline Total Cholesterol & $178,7(46,8)$ & $\mathrm{mg} / \mathrm{dL}$ & 94 & 345 \\
HDL Cholesterol & $35,7(10,9)$ & $\mathrm{mg} / \mathrm{dL}$ & 9 & 61 \\
LDL Cholesterol & $108,9(38,1)$ & $\mathrm{mg} / \mathrm{dL}$ & 23 & 262 \\
Triglycerides & $151,2(64,1)$ & $\mathrm{mg} / \mathrm{dL}$ & 60 & 356 \\
\hline
\end{tabular}

Table 2 shows that the mean value of total cholesterol, HDL cholesterol, LDL cholesterol, and triglycerides of the subjects were $178,7 \mathrm{mg} / \mathrm{dL}, 35,7 \mathrm{mg} / \mathrm{dL}, 108,9 \mathrm{mg} / \mathrm{dL}$, and $151,2 \mathrm{mg} / \mathrm{dL}$. Table 3 shows the results of the atherogenic index of plasma. Table 4 shows the results of small dense LDL. Table 5 shows the results of the coronary artery stenosis degree.

Table 3. The Results of Atherogenic Index of Plasma

\begin{tabular}{llll}
\hline & Mean $(\mathrm{SD})$ & Range & \\
\cline { 3 - 4 } & & Minimum & Maximum \\
\hline $\begin{array}{l}\text { Atherogenic Index } \\
\text { of Plasma }\end{array}$ & $0,26(0,23)$ & $-0,25$ & 0,83 \\
\hline
\end{tabular}

Table 3 showed atherogenic index plasma. It was found that mean atherogenic index plasma was 0,26 .

Table 4. The Results of Small Dense LDL

\begin{tabular}{lllll}
\hline & \multirow{2}{*}{ Mean(SD) } & & Range & \\
\cline { 3 - 4 } & & & Minimum & Maximum \\
\hline SdLDL & $84,31(18,32)$ & $\mathrm{nmol} / \mathrm{mL}$ & 47,86 & 130,04 \\
\hline
\end{tabular}


Table 4 showed small dense LDL

Table 5. The Results of Coronary Artery Stenosis Degree

\begin{tabular}{|c|c|c|c|c|}
\hline & \multirow{2}{*}{ Median } & & \multicolumn{2}{|l|}{ Range } \\
\hline & & & Minimum & Maximum \\
\hline $\begin{array}{l}\text { The degree of coronary } \\
\text { artery stenosis }\end{array}$ & 80 & $\%$ & 50 & 99 \\
\hline
\end{tabular}

Table 5 showed the results of coronary artery stenosis degree

Table 6. The Correlation of Total Cholesterol, HDL Cholesterol, LDL Cholesterol, Triglycerides, AIP, and sdLDL with the Degree of Stenosis

\begin{tabular}{lll}
\hline & \multicolumn{2}{l}{ the Degree of Coronary Artery Stenosis } \\
\cline { 2 - 3 } & $\mathrm{R}$ & $\mathrm{P}$ \\
\hline Total cholesterol $(\mathrm{mg} / \mathrm{dL})$ & 0,104 & 0,390 \\
HDL cholesterol $(\mathrm{mg} / \mathrm{dL})$ & $-0,014$ & 0,912 \\
LDL cholesterol $(\mathrm{mg} / \mathrm{dL})$ & 0,048 & 0,692 \\
Triglycerides $(\mathrm{mg} / \mathrm{dL})$ & 0,201 & 0,095 \\
AIP & 0,126 & 0,299 \\
sdLDL(nmol/mL) & 0,446 & 0,003 \\
\hline
\end{tabular}

Based on Pearson correlation, total cholesterol correlation, HDL cholesterol, LDL cholesterol, triglyceride, IAP, and sdLDL with stenosis degree, shown in table 6.

Table 7. The Linear Regression Analysis

\begin{tabular}{lll}
\hline & \multicolumn{2}{c}{ Degree of Coronary Artery Stenosis } \\
\cline { 2 - 3 } & $\mathrm{R}$ & $\mathrm{P}$ \\
\hline Triglyceride & 0,143 & 0,218 \\
sdLDL & 0,321 & 0,07 \\
\hline
\end{tabular}

Based on the results of linear regression analysis, it was found that SDLDL $(r=0.321)$ had the most correlated correlation when compared with triglycerides $(r=0.143)$ shown in table 7 .

\section{Discussion}

The subjects of this study were 70 ACS patients, with more cases were found in male $(68.6 \%)$ than women $(31.4 \%)$. This result is by the study of Penalva et al. (2008) in Brazil that examined the lipid profiles and the severity of atherosclerosis in ACS patients, where more cases were found in men than women. A study conducted by Samsuria\&Adninta (2015) in Semarang which examined sdLDL and the degree of stenosis in ACS patients also found $81.5 \%$ of the cases in men group.[16]

Gender is one of the risk factors for ACS. Acute coronary syndromes are more common in men than women. This is because women have the estrogen hormone which has the anti- 
atherogenic function, preventing the process of atherosclerosis in blood vessels. The risk increases in postmenopausal women but the incidence remains lower than men of the same age.[17]

The average age of ACS patients in our study was 60.1 (8.9) years old, ranging from 36 to 82 years. This result is similar to the study of Sutamti et al. (2015) and Samsuria\&Adninta (2015) in Semarang which found the mean age of ACS patients of 57.35 (10.96) years old ranging from 37 to 76 years old and 55, 5 (9.55) years old ranging from 34 to 73 years old, respectively.[3]

The strongest independent predictor of ACS is age. The risk increases every 10 years for men. Men over 45 years old and women over 55 years old have conventional risks to develop ACS.[5]

The mean level of total cholesterol of the subjects was 178.7 (46.8) $\mathrm{mg} / \mathrm{dL}$. The mean level of LDL cholesterol of the subjects was 108.9 (38.1) $\mathrm{mg} / \mathrm{dL}$. These results are the same as those obtained by Penalva et al.(2008) who examined lipid profiles in ACS patients. The study reported the level of total cholesterol of 190 (56.8) $\mathrm{mg} / \mathrm{dL}$ and the level of LDL cholesterol of $109(50.8) \mathrm{mg} / \mathrm{dL}$. Khazal obtained different results, 2013 who found an increase in total cholesterol of $214(43.38) \mathrm{mg} / \mathrm{dl}$ and LDL cholesterol of 130.22 (42.35) mg/dL.[16]

The mean HDL cholesterol level in our study was 35.7 (10.9) $\mathrm{mg} / \mathrm{dL}$. The similar result is also observed in a study conducted by Sharma et al. (2014) in India which examined clinical characteristics and angiography in ACS patients. The mean level of HDL cholesterol in the study was $38.39(8,401) \mathrm{mg} / \mathrm{dL}$ (Low HDL based on WHO criteria). The results are different from Penalva et al., (2008) who examined lipid profiles in ACS patients, with the level of HDL cholesterol of $50.2(21.8) \mathrm{mg} / \mathrm{dL} .[16]$

The average triglyceride level in our study was $151.2(64.1) \mathrm{mg} / \mathrm{dL}$ (borderline high triglyceride). This result is similar to that obtained by Luz et al. (2014), who found an increase in triglyceride levels of 167.9 (91.7) $\mathrm{mg} / \mathrm{dL}$. Different results were obtained by Bharwadj et al. (2013) in India who examined the association of AIP with coronary artery stenosis in ACS patients, who reported the triglyceride levels of 140.6 (6.3) $\mathrm{mg} / \mathrm{dL}$ (normally based on NCEP ATP III).[15]

The mean AIP level of our study subjects was 0.26 (0.23). Bharwadj et al., (2013) obtained an AIP score with high cardiovascular risk (0.39). Different results obtained by Frohlich\&Dobiasova (2003) in Canada who studied FerHDL and AIP as the predictors of coronary artery disorders in CHD. The study found an AIP score <0.24.[15]

A study conducted by Dobiasova in 2005 reported that the value of AIP $<0.11$ was associated with a lower risk of cardiovascular disease, AIP values of 0.11-0.24 were associated with intermediate cardiovascular risk, and AIP value> 0.24 was associated with high cardiovascular risk.[17],[18]

The mean sdLDL level of this study subjects was 84.31 (18.32) nmol/L. The median stenosis degree of the study subjects was $80 \%$ with a range of $50 \%-99 \%$. This result is the same as the study by Sutamti et al. (2015) in Semarang which examined the degree of stenosis in ACS patients. They obtained a median stenosis degree of $80 \%$ with a range of $30 \%-90 \%$. Coronary artery stenosis is caused by the process of atherosclerosis that develops slowly with the thickening of the intima due to fibrous accumulation which will gradually constrict the lumen of the coronary artery.[5]

The results of this study found that the most related parameter with coronary artery stenosis in acute coronary syndrome patients was sdLDL. We also found a weak positive and significant correlation between sdLDL and the degree of coronary artery stenosis in ACS patients. 
Small dense LDL is a strong marker to predict the risk of atherosclerosis and CHD. The ability of plasma lipids to migrate into the tunica intima is an important stage in the development of atherosclerosis. The smaller atherogenic lipoprotein particles, the easier the particles migrate and are oxidized, thus accelerating the process of atherosclerosis which will aggravate the degree of coronary artery stenosis.[18]

The limitations of this study are there was no classification of the patients based on the risk factors for ACS. The acute coronary syndrome is a multifactorial disease, which is influenced by many factors, such as hypertension, diabetes mellitus, and smoking habits.

In conclusion, The most related and significant parameter to the degree of coronary artery stenosis in ACS patients at Dr. M. Djamil Hospital Padang is sdLDL. Further research is needed to prove the correlation of AIP and sdLDL with the degree of coronary artery stenosis in ACS patients based on the classification of various risk factors.

\section{References}

[1] Kumar A, Cannon CP, Acute Coronary Syndromes: Diagnosis and Management, Part I", Mayo Clin Proc. 2009;84(10), p 917-38.

[2] Gomar FS, Quilis CP, Leischik R, Lucia A, 2016. Epidemiology of Coronary Heart Disease and Acute Coronary Syndrome. In: Ann Transl Med, Vol 4, p 1-12.

[3] Mihardja LK, Delima, Soetiarto F, Suhardi, Kristanto AY, 2013. PenyakitTidakMenular. In: KementerianKesehatanRepublik Indonesia, penyunting. RisetKesehatanDasar. Jakarta: BadanPenelitiandanPengembanganKesehatanKementeri-anRepublik Indonesia, p. 83-99.

[4] Cunne CM, Kavanagh PM, Menown IA, 2015. A Review of Current Diagnosis, Investigation, and Management of Acute Coronary Syndromes in Elderly Patients. In: CardiolTher, Vol. 4, p 95-116.

[5] Hamm CW, Heeschen C, Falk E, Fox KA, 2014. Acute Coronary Syndromes: Pathophysiology, Diagnosis and Risk Stratification. Di upload dariwww.researchgate.net, p 333-360

[6] National Cholesterol Education Program (NCEP) Expert Panel, Executive Summary of The T; hird Report of The National Cholesterol Education Program (NCEP) Expert Panel on Detection, Evaluation, and Treatment of High Blood Cholesterol in Adults (Adult Treatment Panel III)", JAMA. 2003; 106, p 3143-421.

[7] Wenas M, Jim E, Panda A, HubunganantaraRasio Kadar Kolesterol Total terhadapHigh Density Lipoprotein (HDL) denganKejadianSindromKoronerAkut di RSUP Prof. Dr. R. D. Kandou Manado". Journal e-Clinic. 2017; 5 (2), 183-8

[8] Serdar Z, Aslan K, Dirican M, Sarandol E, Yesilbursa D and Serdar A, Lipid and Protein Oxidation and Antioxidant Status in Patients with Angiographically Proven Coronary Artery Disease". Clinical Biochemistry. 2006; 39, 794-803.

[9] Hamm CW, Heeschen C, Falk E, Fox KAA, Acute Coronary Syndromes: Pathophysiology, Diagnosis and Risk Stratification" in ESC Textbook of Cardiovascular Medicine, $2^{\text {nd }}$ ed, Ed. Serruys PW, Camm AJ, Luscher TF, OUP Oxford, London; 2009. p 333-59.

[10] Char DM, The Pathophysiology of Acute Coronary Syndromes. Advancing the Standard of Care: Cardiovascular and Neurovascular Emegencies, EMREC- International. 2005; p 1-6.

[11] Mitchell RN, Schoen FJ, Blood Vessel. Robbins and Cotran Pathologic Basic of Disease, Elseveir Saunders, 8th edition: 2010. p 542-570.

[12] Poon K \& Walker D, 2011. Indication for Coronary Angigraphy Advances. In: Diagnosis of Coronary Atherosclerosis, Intech, pp 33-68.

[13] Char DM, 2005. The Pathophysiology of Acute Coronary Syndromes. In: Advancing the Standard of care: Cardiovascular and Neurovascular Emegencies, EMREC- International, p 1-6.

[14] Lafta MA, 2014. A Comparative Study for Some Atherogenic Indices in Sera of Myocardial Infarction, Ischemic Heart Disease Patients and Control. In: Journal of Natural of Sciences Research, 4(8), p 917-38. 
[15] Bhardwaj S, Bhattacharjee J, Bhatnagar MK, Tyagi S, Atherogenic Index of Plasma, Castelli Risk Index and Atherogenic Coefficient-New Parameters in Assesingcardiovaskular Risk. Intern $\mathrm{J}$ of Pharmacy and Biologycal Sciences. 2013; vol 3 (3), p 359-364.

[16] Penalva RA, Huoya M, Correia LC, Feitosa GS, Ladeia AM, Lipid Profile and Severity of Atherosclerotic Disease in Acute Coronary Syndrome. Arq bras cardiol. 2008; vol.90(1), p 2429.

[17] Dobiasova M, Frohlich J, Sedova M, Cheung MC, Brown BG, 2011. Cholesterol Esterification and Atherogenic Index ol Plasma Correlate with Lipoprotein Size and Findings on Coronary Angiography. In: Journal of Lipid Research, vol 52, p 566-573.

[18] Frohlich J, Dobiasova M, 2003. Fractional Esterification rate of Cholesterol and Ratio of Triglyserides to HDL-Cholesterol are Powerful Predictors of Positive Findings on Coronary Angiography. In: ClinChem, Vol.49(11), pp1873-1880. 